\title{
ANTIQUITY
}

against another being decided by a least squares criterion. This approach does not make the assumptions of Robinson and Brainerd [3] as to the pattern of cultural change, but simply assumes that that pattern is broadly similar over the material to be studied.

Needless to say Myers worked without benefit of computer, though not without benefit of expert statistical advice. His achievements may serve as a reminder that there is much statistical work to be done at levels far

\section{Kot Diji and Hissar III}

As far back as 1943 Stuart Piggott wrote, 'In any scheme of post-war archaeology in the East, the further elucidation of the Indian prehistoric sequence should be given an important place, not merely to establish this within India, but as a means whereby the stratigraphy and chronology of Iranian sites can be checked from the east no less than from the west' (1943, r82).

The object of this note is to draw attention to a close parallel between a design-motif from Kot Diji and an analogous object from Hissar IIIc, and incidentally to suggest a terminus $a$ $q u o$ for the latter, on the strength of the $\mathrm{C}_{4}$ dates for the various stratified levels of the former (FIG. 1).

The excavations of Kot Diji, Khairpur Division, West Pakistan, brought to light a unique design, painted in black on the dark brown slip over a red background, of a vessel with a very short neck, bulging body and a flat base. It is said to represent a horned deity (Khan, r965). Within the stylized bucranian horns on either side is seen a six-petalled flower outlined with black and filled with white. The gracefully curved horns are painted in black, but additionally these bear, at regular intervals, an oval, leaf-like motif done in white. From the junction of the horns seems to 'hang' down an elongated human head, its chin and cheeks shown in black dots, the low forehead, and the upper part of the long drooping ears in solid black.

The vessel was found intact in layer $3 \mathrm{~A}$, and is fairly large $(33 \mathrm{~cm}$. broad, and $20 \cdot 3 \mathrm{~cm}$. total more fundamental than that of interpretative seriation and that for a great deal of quantitative work in archaeology a computer is a dispensable luxury.

THURSTAN SHAW and S. G. H. DANIELS

[r] F. Hole and M. Shaw, Computer Analysis of Chronological Seriation (Houston 1968).

[2] O. H. Myers, "Abka re-excavated', Kush, 6, 1958.

[3] W. S. Robinson and G. W. Brainerd, 'A method for chronologically ordering archaeological deposits', American Antiquity, xvi, I951, 293.

height). Stratigraphically it is assigned to the late Kot Diji culture, from which was also found a slightly smaller vessel with the typical fish-scale design (Khan, I965, 59, fig. I6, pl. XVII). Though Dr Khan assigns both vessels to the Kot Diji Culture, according to his own statement (p. 15), layer 3 is Harappan and layer $3 \mathrm{~A}$ transitional, so that both these layers could well be Harappan because in the latter $(3 \mathrm{~A})$ were present both Harappan and pre-Harappan (or Kot Diji) cultural elements.

This little detail about the stratigraphical position of the vessel is necessary when we discuss the ancestry of the design. For it is partly Iranian and partly Indian (Harappan).

The immediate ancestor of this human head and bucranium with flowers set in each of its wings seems to be Iranian, particularly Hissar IIIc, where five gold sheets with a mouflon (wild mountain sheep of southern Europe) according to Schmidt (1937), or ibex (Gordon, I961), were found in a hoard. The horn sheets bore additionally seven pairs of perforations which pierced the long, coiled horns and the beard of the animal so that this gold ornament - probably with some ritualistic significancecould be stitched on cloth or leather as inferred by Schmidt ( $937, x 89$ ).

For the inset flower motif we have to go to earlier Iranian periods such as Hissar IB (Schmidt, 1937, pl. v), and Sialk (Ghirshman, 1939) where, within the horns curving upwards, and forming almost a circle, are found one or two flowers. So long as the motif remained in Iran, the original animal head 
NOTES AND NEWS
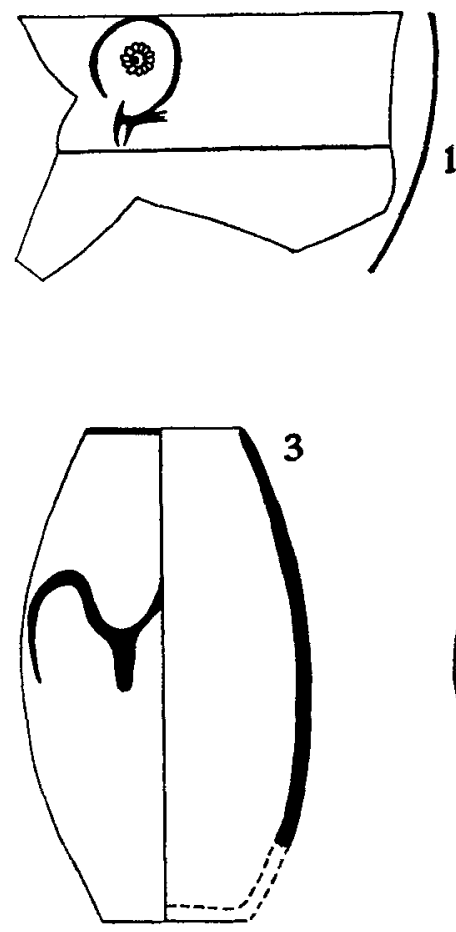

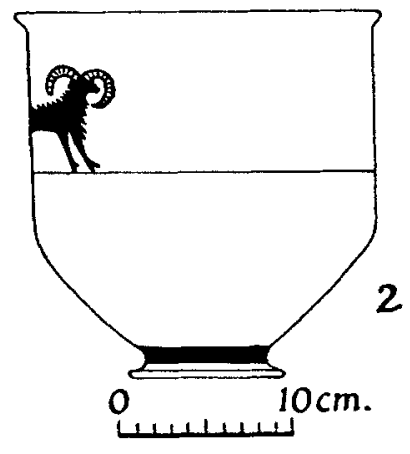

2
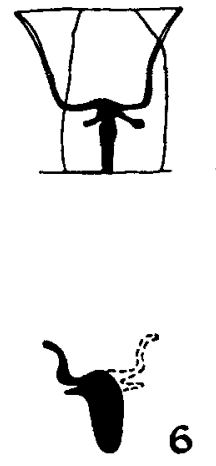

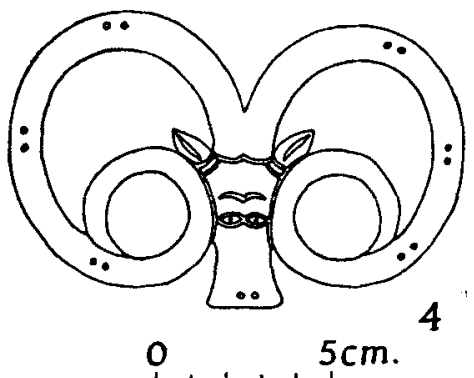

5
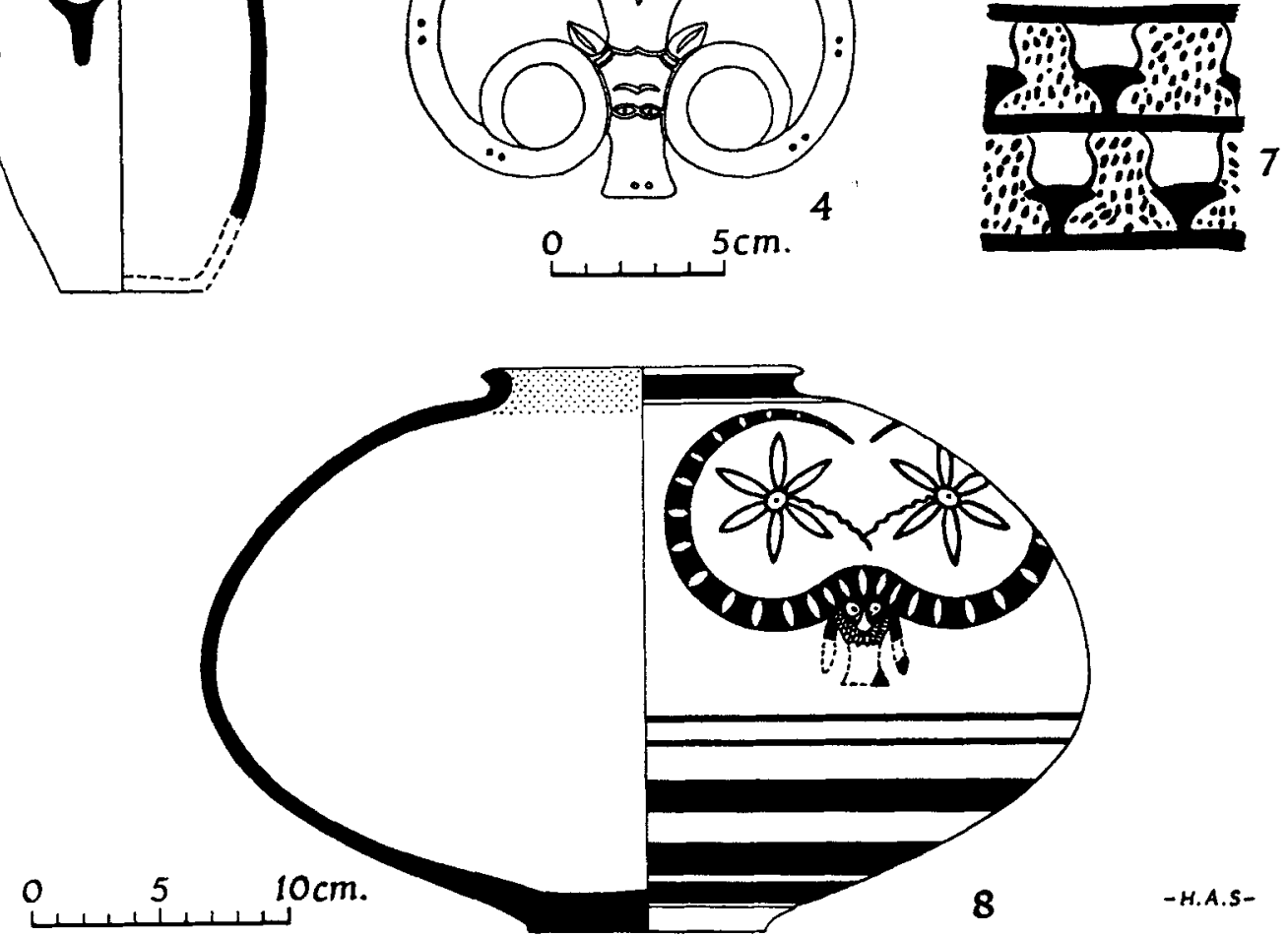

Fig. I. Some of the stages in the development of the bucranian design-motif in Iran and the IndoPakistan subcontinent. I: Stylized ibex head with one horn shown almost like a circle with a lotus-like flower set in it (Sialk III). 2: Ibex shown in a natural way (Sialk III). 3: Ibex, partly stylized (Loralai, Periano). 4: Mouflon head of gold from Hoard I (Hissar IIIc). 5-7: Bucrania and mouflon designs (Tell Halaf). 8: Humanized bucranium head from Kot Diji, with flowers set within the incurved horns, as in Sialk III. The white dashes on the black painted horns are perhaps in imitation of the punctures on the Hissar gold mouflon head. For references to the drawings see p. I44 


\section{ANTIQUITY}

could be easily recognized. But on reaching Sind, it was humanized, and the mouflon horns were replaced by those of a bull.*

The facial features-beard, eyes and the nose-are well defined, as. in the Iranian, but the ears droop down instead of being raised up, as in the original. In Kutch and Saurashtra this particular species of bull is at home today, and has been at least from Harappan times (c. $2300 \mathrm{BC}$ ).

The next stage was the representation of this deity on the seal, as at Mohenjo-daro (Marshall, 1931; Mackay, 1938). Thus a gradual Indianization of the motif, first seen in Iran for some millennia, is witnessed. While this small piece of evidence helps in understanding the Iranian or Western Asiatic cultural traits in the Harappan, it also helps in dating the third cultural phase at Hissar. Gordon (195I) rejected the dating of McCown, which ranged between 2700-2300 BC or 2300-2,100 BC, and suggested a much lower date of 2000-1500 BC. This was also the view of Piggott (I943, I80), who equated Hissar III with the Jhukar Culture (Chanhu-daro II).

At Kot Diji, the pre-Harappan or Kot Diji Culture has four $\mathrm{CI}_{4}$ dates (Khan, 1965,85 ): $1975 \mathrm{BC}, 22 \mathrm{II} \mathrm{BC}, 2 \mathrm{I} 33 \mathrm{BC}$, and $247 \mathrm{I} \mathrm{BC}$. Thus the Iranian motif, with the other Iranian traits, should have reached Kot $D_{i j i}$ by at least

* Though in our present knowledge a bull with such long, incurving horns appears in Period II at Rana Ghundai, in what is called the Bull Vase phase (Ross, 1946).
$2000 \mathrm{BC}$. If so, at the type site, Hissar, it should be a century or two earlier, that is $2200 \mathrm{BC}$.

H. D. SANKALIA

\section{BIBLIOGRAPHY}

GHIRSHMAN, R. I939. Fouilles de Sialk, vol. I, pl. LXXI, S.I 800; pl. LXXxI, B.5.

GORDON, D. H. I95I. 'The Chronology of the Third Cultural Period at Tepe Hissar', Iraq, III, 60 .

196r. 'Dating the Third Cultural Phase at Tepe Hissar', Iraq, XIII, 54.

KHAN, F. A. I965. 'Excavations at Kot Diji', Pakistan Archaeology, no. 2A, 57, fig. 16, and pl. xvirb.

MACKAY, E. J. H. 1938. Further Excavations at Mohenjo-daro, vol. II, pl. LXxxII, $x b-c$, and pl. XCrx, $A$.

MARSHALL, SIR JOHN. I931. Mohenjo-daro and the Indus Civilization, vol. 1, pl. XII, 17, 18; pl. XIII, $x$.

PIGGOTT, S. 1943. 'Dating the Hissar Sequencethe Indian Evidence', ANTIQUITY, 182.

Ross, E. J. 1946. 'A Chalcolithic Site in Northern Baluchistan', Gournal of Near Eastern Studies, v, 303 , pl. IX, 1 .

SCHMIDT, E. F. 1937. Excavations at Tepe Hissar, Damghan, I89, fig. III, and pl. XLVI.

SULLIVAN, H. P. I964. 'A Re-examination of the Religion of the Indus Civilization', History of Religion, vol. IV, II 5.

References for Fig. I.

I: Ghirshman, 1939, pl. LxxxI, B.5.

2: Ibid, pl. LxxI, S. 1800 .

3: Walter A. Fairservis, Archaeological Surveys in the Zhob and Loralai Districts, West Pakistan (New York, 1959), 377, fig. 68, b.

4: Schmidt, I937, I89, fig. III, and pl. XLVI, H.3210.

5-7: Iraq, III, I9, fig. 26; I, 7, 9.

8: Khan, 1965, fig. 16 and pl. xvirb.

\section{Radiocarbon Dates for the South Street Long Barrow, Wiltshire}

Four radiocarbon dates have been obtained for the South Street Long Barrow, North Wiltshire [I]. The measurements were made by the British Museum Research Laboratory.

They are as follows:

Charcoal on the surface of the buried soil beneath the barrow mound:

$$
\mathrm{BM}-3562810 \pm 130 \mathrm{BC}
$$

Bone (Bos sp. vertebrae) on the bottom of the north ditch:

$$
\text { BM-357 } 275^{\circ} \pm \mathrm{I} 35^{\mathrm{BC}}
$$

Red deer antler on the bottom of the north ditch:

$\mathrm{BM}-35^{8 \mathrm{a}} 2670 \pm \mathrm{I} 40 \mathrm{BC}$

Red deer antler embedded in the mound: BM-358b $2580 \pm 110 \mathrm{BC}$

These dates are of interest for several reasons. First, they place the construction of the barrow in the first half of the 3 rd millennium BC. They compare well with the dates for two other long barrows in the area, Wayland's Smithy II, $2820 \pm 130$ BC (I-I468 [2], and Nutbane, 